\title{
Corrigendum: Polyamine regulates tolerance to water stress in leaves of white clover associated with antioxidant defense and dehydrin genes via involvement in calcium messenger system and hydrogen peroxide signaling
}

\author{
Zhou Li, Yan Zhang, Dandan Peng, Xiaojuan Wang, Yan Peng *, Xiaoshuang He, \\ Xinquan Zhang, Xiao Ma, Linkai Huang and Yanhong Yan \\ Department of Grassland Science, College of Animal Science and Technology, Sichuan Agricultural University, Chengdu, \\ China
}

Keywords: antioxidant, dehydrin, gene expression, oxidative damage, polyamine, regulation, white clover (Trifolium repens)

\section{A corrigendum on}

\section{OPEN ACCESS}

Edited and reviewed by: Ken Yokawa,

University of Bonn, Germany

${ }^{*}$ Correspondence: Yan Peng

pengyanlee@163.com

Specialty section: This article was submitted to

Plant Physiology,

a section of the journal

Frontiers in Physiology

Received: 19 January 2016 Accepted: 03 February 2016 Published: 15 February 2016

Citation:

Li Z, Zhang Y, Peng D, Wang $X$, Peng $Y$, He $X$, Zhang $X$, Ma $X$, Huang $L$

and Yan $Y(2016)$ Corrigendum:

Polyamine regulates tolerance to water stress in leaves of white clover associated with antioxidant defense and dehydrin genes via involvement in calcium messenger system and hydrogen peroxide signaling. Front. Physiol. 7:52. doi: 10.3389/fphys.2016.00052
Polyamine regulates tolerance to water stress in leaves of white clover associated with antioxidant defense and dehydrin genes via involvement in calcium messenger system and hydrogen peroxide signaling

by Li, Z., Zhang, Y., Peng, D., Wang, X., Peng, Y., He, X., et al. (2015). Front. Physiol. 6:280. doi: 10.3389/fphys.2015.00280

In the paper titled "Polyamine regulates tolerance to water stress in leaves of white clover associated with antioxidant defense and dehydrin genes via involvement in calcium messenger system and hydrogen peroxide signaling," there was a typing error in the section of "Introduction," which should be corrected. In the first paragraph in the section of "Introduction," "putrescine (Put), spermidine (Spd) and spermine (Spd)" should be corrected to "putrescine (Put), spermidine (Spd) and spermine (Spm)." No other correction is needed.

\section{AUTHOR CONTRIBUTIONS}

All authors listed, have made substantial, direct and intellectual contribution to the work, and approved it for publication.

Conflict of Interest Statement: The authors declare that the research was conducted in the absence of any commercial or financial relationships that could be construed as a potential conflict of interest.

Copyright $\odot 2016$ Li, Zhang, Peng, Wang, Peng, He, Zhang, Ma, Huang and Yan. This is an open-access article distributed under the terms of the Creative Commons Attribution License (CC BY). The use, distribution or reproduction in other forums is permitted, provided the original author(s) or licensor are credited and that the original publication in this journal is cited, in accordance with accepted academic practice. No use, distribution or reproduction is permitted which does not comply with these terms. 